\title{
The effect of V、Ni microalloying on microstructure and properties of bainite steel
}

\author{
YUNLEI LIN ${ }^{1, a}$, QINGYUE ZHOU ${ }^{2, b}$ \\ ${ }^{1}$ Postgraudate Department, China Academy of Railway Sciences, Beijing, China \\ ${ }^{2}$ Metals \& Chemistry Research Institute, China Academy of Railway Sciences, Beijing, China \\ acarslinyunlei@163.com, bhouqingyue93480@126.com
}

\section{Keywords: Bainitic Steel; Microalloying; Bainite}

Abstract. In order to obtain a rail steel with high strength, high toughness and good resistance against contact fatigue failure, vanadium and niobium were added into the bainite steel, and roles of $\mathrm{V}$ and $\mathrm{Ni}$ were discussed. With the addition of $\mathrm{V}$ and $\mathrm{Ni}$, the bainite steel is obtained grain refining, high strength and toughness. The mechanical properties are as follows: $R \mathrm{~m}$ is $1467 \mathrm{MPa}, R \mathrm{p}_{0.2}$ is $850 \mathrm{MPa}, \mathrm{A}$ is $17 \%$, $\mathrm{Z}$ is $46 \%$, hardness is $44 \mathrm{HRC}$, and $\alpha_{\mathrm{k}}$ is $60 \mathrm{~J} / \mathrm{cm}^{2}$.

\section{Introduction}

Rail is a crucial material for railway, and the service condition of rail becomes more and more critical as with fast development of high-speed and heavy-load railway. There are some problems in existing railroads. $1300 \mathrm{MPa}$ grade heat treated rail, which elongation is greater than $8 \%$, impact toughness is greater than $30 \mathrm{~J}$, hardness of top face is about $370-410 \mathrm{HB}$, is laid in small radius curve. But defects are unavoidable: side abrasion of upper rail is serious and swap block defects appear on lower rail. In order to meet the increased needs of railway development in China, bainite steel has received widespread attention for high strength, high toughness, good resistance again wear and contact fatigue failure. In 2002, Metals \& Chemistry Research Institute, China Academy of Railway Sciences had worked with An Steel to develop a 1200MPa grade air-cooling bainite steel. The following observation results reveal that the rail had better general properties than pearlite steel.

At present, the main idea of developing bainite rail is alloying and heat treatment of air-cooling bainite ${ }^{[1-4]}$. Dong Tianshun et al. ${ }^{[5]}$ studied microstructure and properties of bainite/martensite dual phase steel after heat treatment, the results showed that the multiphase steel had good wear resistance, corresponding performances of multiphase steel after normalization and tempering were as follows: $R_{\mathrm{m}}$ is $1731.7 \mathrm{MPa}, \mathrm{HRC}$ is $51.7, \alpha_{\mathrm{k}}$ is $20.6 \mathrm{~J} / \mathrm{cm}^{2}$. Bao Xirong et $\mathrm{al}^{[6]}$ designed a high strength and toughness bainitic steel for rail, and La was used together with $\mathrm{Mn}, \mathrm{Si}, \mathrm{Cr}$, Mo to enhance hardenability. It turned out that the role of $\mathrm{La}$ is to improve the hardenability of steel by promoting the strengthening effect of $\mathrm{Mn}, \mathrm{Cr}$ and $\mathrm{Mo}$, and to reduce the bainite characteristic temperature (Bs). Zhao Jiali et al ${ }^{[7]}$ researched a 70Si3MnCrMo bainitic steel, the steel is able to obtain good integrated mechanical properties after austempering and continuous cooling treatment, $R_{\mathrm{m}}$ is $2138 \mathrm{MPa}$, product of strength and ductility is $26.4 \mathrm{GPa} . \%$, HRC is 55.9 .

In this paper, in order to obtain a rail steel with high strength, high toughness and good resistance against contact fatigue failure, vanadium or niobium are added into the bainite steel, and roles of $\mathrm{V}$ and $\mathrm{Ni}$ are discussed.

\section{Materials and experimental procedure}

The main additive elements of Bainite steel alloying are: $\mathrm{C}, \mathrm{Mn}, \mathrm{Si}, \mathrm{Ni}, \mathrm{Mo}, \mathrm{Nb}, \mathrm{Ti}, \mathrm{V}, \mathrm{CR}$, etc., and their effects are as follows:

$\mathrm{C}$ : Carbon is functioned as solution strengthening element, it can increase the strength of steel and stabilize the austenite, but it will reduce the toughness and plasticity when the content is high. $\mathrm{B}_{\mathrm{S}}$ point 
decreases with the increase of carbon. The added content of carbon depends on service conditions during actual use.

Mn: Manganese can improve the hardenability of bainite, and reduce the $B_{S}$ and $M_{S}$ point. It controls the bainite transition and improves strength and hardenability of bainite steel. In addition it shows that Mn can refine the grain in mild steel. However, high Mn content will increase the superheat sensitivity and temper brittleness of steel, and decrease the weldability.

Si: Silicon is one of the strengthening bainite elements and deoxidation elements. It plays solution strengthen role, which can improve the strength and wear resistance of steel. At the same time, silicon can inhibit the precipitation of carbides and increase the stability of supercooled austenite.

$\mathrm{Cr}$ : Chromium can lower the $\Delta \mathrm{B}_{\mathrm{S}} / \Delta \mathrm{M}_{\mathrm{S}}$ ratio and reinforce matrix uniting with other elements. It can be solid soluble in ferrite, but also form carbide. $\mathrm{C}$ curve would shift to the right if chromium is added.

Mo: Molybdenum can improve the hardenability of steel, postpone the transformation in high temperature significantly and thus the pearlite transition zone separates from the bainite transition zone of $\mathrm{C}$ curve, which is the key factor for bainite steel in the obtaining bainite in air-cooling condition.

$\mathrm{Ni}$ : Niobium can stabilize the supercooled austenite, reduce the $\mathrm{B}_{\mathrm{S}}$ point, refine the bainite grain, and improve the toughness and plasticity of the steel. $\mathrm{Ni}$ is an essential element for high impact toughness.

$\mathrm{V}$ : Vanadium plays a role of precipitation enhancement, vanadium carbide formed in the cooling process of hot rolling.

The lower the $\mathrm{B}_{\mathrm{S}}$ point, in theory, the more lower bainite in transformation products, the better combination of strength and toughness. And the higher the $\Delta B_{S} / \Delta M_{S}$ ratio, the narrower the temperature range of bainite structure growth, the finer the microstructure. It improves the obdurability of steel, similar to the role of refining the grain. So it is necessary to consider each alloyed elements and their influences.

In order to study the effect of $\mathrm{V}$ and $\mathrm{Ni}$ on the microstructure and properties of bainite steels, the paper designs three kinds of bainite steels, and chemical compositions are shown in Table 1 . The tested steels were produced by vacuum induction furnace smelting, and pouring into 6kg ingot as a blank material, then hot rolling, in accordance with the requirements of Tab 1. The forging process is: heating the ingot to $1150{ }^{\circ} \mathrm{C}$ at $150-200^{\circ} \mathrm{C} / \mathrm{h}$ and keep $3 \mathrm{~h}$, initial forging temperature is $1150{ }^{\circ} \mathrm{C}$, the final forging temperature is greater than $950^{\circ} \mathrm{C}$, the forging ratio is about 6 , burying the ingot in sand for retarded cooling after forging. Samples for testing mechanical properties and metallographic microstructure analysis were obtained from billet steel. The mechanical tests were carried by MTS system, the Charpy-U tests were tested by a pendulum impact testing machine, the hardere tested by a pendulum impact testing machine, the hardness tests were tested by a rockwell hardness tester, the microstructure analysis were tested by DMI 5000M Optical Microscope. The microstructure analysis samples were first mechanical ground, then chemical polished and corroded by $4 \%$ Nital.

Table 1 Chemical compositions of the tested steels (mass fraction, \%)

\begin{tabular}{|c|c|c|c|c|c|c|c|}
\hline \multirow{2}{*}{ Number of Samples } & \multicolumn{7}{|c|}{ Chemical compositions $/ \%$} \\
\hline & $\mathrm{C}$ & $\mathrm{Si}$ & $\mathrm{Mn}$ & $\mathrm{Cr}$ & Mo & $\mathrm{Ni}$ & $\mathrm{V}$ \\
\hline 1 & 0.29 & 1.70 & 1.80 & 1.04 & 0.39 & 0.35 & 0.09 \\
\hline 2 & 0.29 & 1.70 & 1.85 & 1.02 & 0.39 & 0.38 & \\
\hline 3 & 0.29 & 1.69 & 1.83 & 0.99 & 0.37 & & 0.13 \\
\hline
\end{tabular}

\section{Results and analysis}

Effect of Vanadium on properties and microstructure. The mechanical properties of the tested steels are shown in Table 2, and the microstructure comparison is shown in Fig. 1. According to Table 1 , the No.1 steel is used as the contrast steel, the base content has both $\mathrm{V}$ and Ni. The content of No.2 steel is removed V, on the basis of No.1 steel. 
The tensile strength of No.1 steel is $1467 \mathrm{MPa}$, yield strength is $850 \mathrm{MPa}$, elongation rate is $17 \%$, section shrinkage rate is $46 \%$, hardness $44 \mathrm{HRC}$, and impact toughness at room temperature is 60 $\mathrm{J} / \mathrm{cm}^{2}$. The tensile strength of No.2 steel is $1413 \mathrm{MPa}$, yield strength is $774 \mathrm{MPa}$, elongation rate is $13 \%$, section shrinkage rate is $33 \%$, hardness $41 \mathrm{HRC}$, and impact toughness at room temperature is $68 \mathrm{~J} / \mathrm{cm}^{2}$. When compared with the No.2 steel, No.1 steel has good combination of strength and toughness, the strength and hardness are greater, the impact toughness is lower, the elongation and the section shrinkage are all higher than the No.2 steel, with good toughness and plasticity. The microstructure of No.1 Steel is bainite with a small amount of ferrite, the grain size of $20 \mu \mathrm{m}$. The microstructure of No.2 steel is bainite and the grain size is about $45 \mu \mathrm{m}$. The addition of $0.09 \% \mathrm{~V}$ makes the microstructure of No. 1 steel obviously refined, and the strength and hardness are both improved. Zhu Yulong et $\mathrm{al}^{[8]}$ studied the effect of Vanadium on microstructure and hardness of BDI. They discovered that $\mathrm{V}$ was benifical to bainite transformation of BDI, to increase the nucleation rate of bainite, to refine the microstructure of bainite and then improve the amount of bainite transformation. $\mathrm{V}$ could increase the hardness by dispersion strengthening.

Table 2 Mechanical properties of the tested steels

\begin{tabular}{ccccccc}
\hline \multirow{2}{*}{ Number of Samples } & \multicolumn{5}{c}{ Mechanical properties } \\
\cline { 2 - 6 } & Rm/MPa & Rp0.2/MPa & A /\% & Z /\% & Hardness/HRC & $\begin{array}{c}\text { Impact } \\
\text { toughness }\left(\mathrm{J} / \mathrm{cm}^{2}\right)\end{array}$ \\
\hline 1 & 1467 & 850 & 17 & 46 & 44 & 60 \\
2 & 1413 & 774 & 13 & 33 & 41 & 68 \\
3 & 1409 & 807 & 14 & 36 & 38 & 59 \\
\hline
\end{tabular}

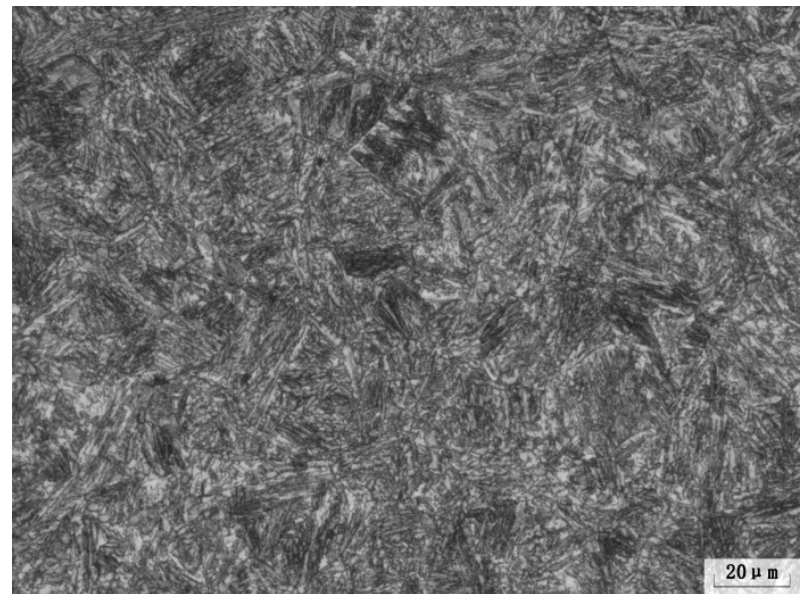

(a) No.1

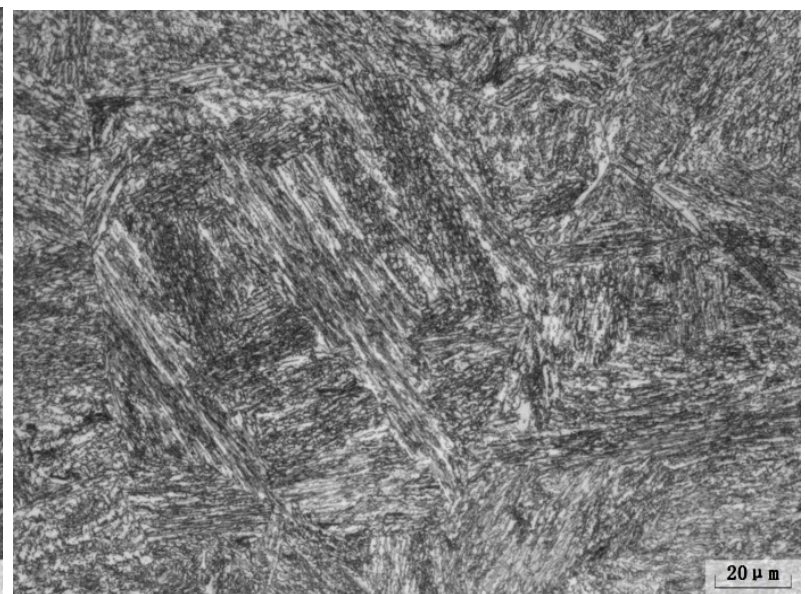

(b) No.2

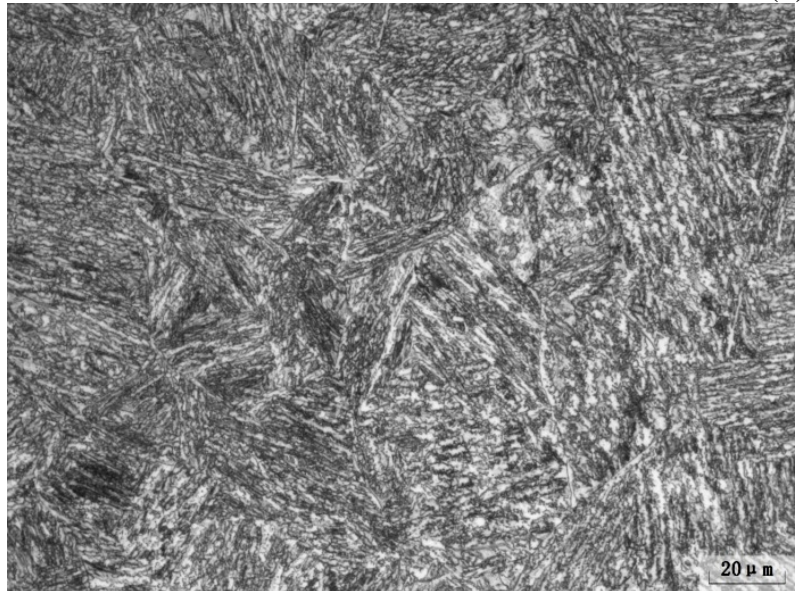

(c) No.3

Fig. 1 Microstructures of the tested steel

Effect of Niobium on properties and microstructure. According to Table 1, the content of No.3 steel is removed Ni, on the basis of No.1 steel. As results shows, the tensile strength of No.3 steel is 
$1409 \mathrm{MPa}$, yield strength is $807 \mathrm{MPa}$, elongation rate is $14 \%$, section shrinkage rate is $36 \%$, hardness is $38 \mathrm{HRC}$, and impact toughness at room temperature is $59 \mathrm{~J} / \mathrm{cm}^{2}$. Compared with No.1 Steel, the tensile strength, yield strength, elongation, section shrinkage and hardness of the test steel without $\mathrm{Ni}$ were decreased, and the impact toughness similar to $60 \mathrm{~J} / \mathrm{cm}^{2}$ (impact toughness of No.1 steel). The microstructure of No.3 steel is bainite, the original austenite grain boundary is clearly visible, and the grain size is about $30 \mu \mathrm{m}$. With the addition of $0.35 \% \mathrm{Ni}$, and the grain of No.1 steel is refined. Chen Yulai et $\mathrm{al}^{[3]}$ had researched the effect of Mo and Ni on microstructure and mechanical properties of bainite steel. The results showed that both tensile strength and toughness of carbide-free bainite ultra-high strength steel could significantly improve by adding Ni. The role of refining bainite ferrite grain was reflected too. The addition of $\mathrm{Ni}$ could postpone the transformation of high temperature ferrite, and lower the $\mathrm{M}_{\mathrm{S}}$ point.

\section{Conclusions}

With the addition of $0.09 \% \mathrm{~V}$ and $0.35 \% \mathrm{Ni}$, the steel obtains a good combination of strength and toughness, the tensile strength is $1467 \mathrm{MPa}$, yield strength is $850 \mathrm{MPa}$, elongation rate is $17 \%$, section shrinkage rate is $46 \%$, hardness $44 \mathrm{HRC}$, and impact toughness at room temperature is $60 \mathrm{~J} / \mathrm{cm}^{2}$.

Adding V/Ni can remarkably improve both strength and toughness and refine the banite grain, but V and $\mathrm{Ni}$ have different effects. In a way, adding trace amount $\mathrm{V}$ has remarkable impacts on strengthen, toughness, and refining the grain.

\section{Acknowledgements}

This work was financially supported by Main Objects of National Key Research and Development (R\&D) Plans Foundation (2017YFB0304500).

\section{References}

[1] Siwecki T, Eliasson J, Lagneborg R, et al. Vanadium Microalloyed Bainitic Hot Strip Steels[J]. Isij International, 2010, 50(5):760-767.

[2] Liu Fengshou, Chen Zhaoyang, Zhang Yinhua, et al. Development of the bainitic switch rail with high-strength and wear-resistance[J]. China Railway Science, 2011, 32(2):139-143.

[3] Chen Yulai, Dong Changzheng, Cai Qingwu, et al. Efect of Mo and Ni on microstructure and mechanical properties of carbide-free bainite ultra-high strength steels[J]. Journal of Materials Engineering, 2013(9):16-21.

[4] Feng Ziling, Cui Chenglin, Yang Yanling. Influence of heat treatment on performance of bainite rail and pearlite rail thermite welding joint[J]. Railway Engineering, 2016(10):116-120.

[5] Dong Tianshun, Li Guolu, Liu Jinhai, et al. Heat treatment and property of medium carbon Si-Mn multiphase wear-resistant steel[J]. Transactions of Materials and Heat Treatment, 2014, 35(7):75-80.

[6] Bao Xirong, Wang Junan, Wang Xiaodong, et al. Study on a Mn-Cr-Mo-La air-cooled bainitic steel for rails[J]. Journal of the China Railway Society, 2017, 39(4):118-125.

[7] Zhao Jiali, Zhang Fucheng, Yu Baodong, et al. Bainite microstructure and its tempering stability of 70Si3MnCrMo steel[J]. Iron and Steel, 2017, 52(1):71-80.

[8] Zhu Yulong, Chen Dilin, Zhai Qijie. Effect of vanadium on structure and hardness of BDI[J]. Journal of University of Science and Technology Beijing, 22(1):000041-43. 